\title{
Relation of Normal Blood Oxygen Level with Presence or Absence of Chin Dimple
}

\author{
Muhammad Imran Qadir, Noor Arif* \\ Institute of Molecular Biology and Biotechnology, Bahauddin Zakariya University, Multan, Pakistan \\ *Corresponding Author: Noor Arif, Institute of Molecular Biology and Biotechnology, Bahauddin \\ Zakariya University, Multan, Pakistan
}

\begin{abstract}
Objective of the present study was to correlate chin dimple with level of oxygen in blood. Level of oxygen is an extent that is present in human RBCs. The body almost deals with the blood oxygen level. An estimation of our blood oxygen is called as oxygen immersion level. When the blood has not enough oxygen, body may get diseases that are caused by low level of oxygen. An aggregate of 200 subjects took part in this research. Subjects were students in Bahauddin Zakariya University, Pakistan. Relation of normal blood oxygen level with chin dimple was checked. Blood oxygen level of all subjects was examined. The value of $p$ was more than significant value. It was assumed from research that there was no noteworthy connection of normal blood oxygen level with presence or absence of chin dimple.
\end{abstract}

Keywords: blood oxygen level, hypoxemia, oxygen immersion level, jaw dimple, chin dimple

\section{INTRODUCTION}

Amount of oxygen in blood is a proportion of oxygen in RBCs. Body nearly manages the level of oxygen in blood. Keeping up the exact equalization of oxygen-immersed blood is crucial to the health. Most kids and grown-ups don't have to screen their oxygen level. Various specialists won't check it except if body is appearing of an issue such as shortness to breath or chest torment. However, individuals with incessant well-being conditions many need to screen their oxygen level. This incorporates asthma, coronary illness and ceaseless obstructive pneumonic sickness (COPD). In these cases, observing level of oxygen in blood can help decide whether medicines are working, or in the event that ought to be balanced. An estimation of oxygen level in blood is called as $\mathrm{O}_{2}$ immersion level. It is also called as $\mathrm{PaO}_{2}$ and an $\mathrm{O}_{2}$ saturation when operating a heartbeat bull or oximeter. These scales will permit to figure out what the outcome may mean:

Normal: An ordinary ABG oxygen level for good physical shape lungs fall over somewhere in the extent of 80 and 100 millimeters of mercury $\mathrm{mmHg}$. On the off chance that a pulse oximeter guessed the blood oxygen level, an ordinary perusing is somewhere in the reach of 95 and $100 \%$.

Below normal: An underneath typical blood oxygen level id called hypoxemia. Hypoxemia is regularly reason for restlessness. Extreme hypoxemia is due to lower oxygen level. This can initiate prompt inconveniences in body tissue and organs. $\mathrm{PaO} 2$ perusing beneath $80 \mathrm{mmHg}$ or a pulse ox beneath $95 \%$ is viewed as low. It is vital to be familiar with what is ordinary for people, notably in the event that people have a constant lung condition.

Above normal: If our breathing is unassisted, it is troublesome for the oxygen level to be unduly high. As a rule, high oxygen level takes place in individuals who utilize additional oxygen. This can be spotted on an ABG.

When the body has not enough oxygen level, it may perhaps pick up certain diseases as hypoxemia or hypoxia. These are perilous ailments. Due to low level of $\mathrm{O}_{2}$ in body organs, they can be out of action. Disease as Hypoxemia that is low level of oxygen in blood can cause hypoxia that is low $\mathrm{O}_{2}$ level in tissue. Hypoxia is now and again used to depict the two issues.

Chin dimples, cleft chin or butt chin are numerous distinct terms for this particular feature for the face. Many people have y-molded pit on their jaw; others acquire it after some time. The jaw dimple happens to be one of the Mendelian attributes in humans. This jaw dimple is an acquired quality 
where the overwhelming genes cause this fissure. For those with chin dimple, the jaw creates as two separate parts on a baby and when there is slight deviation in arrangement during the intertwining of the two parts it results in split jaw or chin dimple. While, the individuals who create it normally have it since one portion of the jaw becomes bigger or longer than the other, causing the dimple at the jaw where the two parts fuses. The cleft in a jaw shows up in assorted variety including vertical crease, y molded crease and round empty in a chin. It tends to be inside and out from a somewhat visual wrinkle to a very visual wrinkle. The individual having this characteristic normally gets the consideration of individuals and stays in focal point of interest. The recurrence of parted jaw shifts broadly among various populaces; Indian populaces run from 4 to 71 percent chin dimple. Split jaws are an acquired attribute that relies on the predominant and latent genes of the two guardians. Cleft chin is increasingly normal in European populaces, for example, Germany, where rates reach around 10 percent in men. People having jaw dimple have certain qualities. Ladies with chin dimple have the initiative forces and can adapt to the glooms with less distress. Men with chin dimple are energetic, daring and yearning.

Normal blood oxygen level with chin dimple is the objective of this study.

\section{Materials AND Methods}

\subsection{Measurement of Peripheral Oxygen Level}

Pulse oximetry is an insensitive way for observing oxygen saturation. A sensor gadget is put on a thin part of the patient body more often a fingertip or ear cartilage. The sensor passes two wavelengths of lights through body parts. It quantifies the varying absorbance at each of the wavelengths. During a pulse oximetry analysis, we set a tiny clasp like gadget on the tip of finger. Small light emissions went across the blood in the finger, approximating the volume of oxygen. We kept the clasp on for whatever the length of time desired to observe the oxygen level and pulse rate. When the test was come to an end, the clasp was detached and we observed the reading of oxygen level in blood.

\subsection{Project Design}

An aggregate of 200 subjects took part in this up to date research. The participants were the students of Bahauddin Zakariya University. A survey was performed to examine the relation of blood oxygen level with chin dimple of various subjects.

\subsection{Statistical Analysis}

$t$-test analysis was used to perform statistical analysis.

\section{RESUlts}

Relation of normal blood oxygen with chin dimple is given in Table.1. Results showed that ratio of people with chin dimple was less than the people with no chin dimple. The value of $p$ was 0.75 that was non-significant. Overall results showed that there is no significant relation of normal level of oxygen in blood chin dimple among students.

Table1. Relation of normal blood oxygen (Mean \pm S.D) with presence or absence of chin dimple

\begin{tabular}{|c|c|c|c|}
\hline Gender & Presence of chin dimple & Absence of chin dimple & $p$ value \\
\hline Male & $94.75 \pm 7.88$ & $96.32 \pm 4.50$ & 0.59 \\
\hline Female & $96.20 \pm 5.56$ & $96.03 \pm 4.56$ & 0.85 \\
\hline Combined & $95.98 \pm 5.91$ & $96.26 \pm 4.46$ & 0.75 \\
\hline
\end{tabular}

(where $p>0.05$ ) that is non-significant

\section{DISCUSSION}

Studies based on questionnaire have given a central advancement in latest studies.

Amar S Bhogal and Ali R Mani did a study on Oxygen Saturation Variability in well individuals. They observed that pulse oximetry is routinely utilized for checking patients' oxygen immersion levels with respect to the physiological trait. The point of this examination was to describe the example of OSV utilizing an uncommon parameter; the normality, the self-likeness and the multifaceted nature. The investigation population comprised of 36 individuals. The "youth" population comprised of 20 people and the "old" population comprised of 16 people. This investigation had portrayed OSV 
utilizing previous apparatuses. They demonstrated that investigation of pulse oximetry signals conveys data about body oxygenation. Another experiment was done on low oxygen saturation and mortality rate. Monica Linea, Tom Wilsgaard and Hasse Melbye did a study on this. The point of this examination was to decide if low oxygen level is related with more mortality rate in the young population. Pulse oximetry was performed in 5,152 members in a cross-sectional overview in Norway. Reason for death was gathered into four classifications: cardiovascular infection, malignant growth, pneumonic ailment, and others. Mortality caused by aspiratory sicknesses was fundamentally connected with $\mathrm{SpO}$ 2. Low oxygen level was connected with expanded mortality and mortality is caused by pneumonic sicknesses.

\section{CONCLUSION}

It was assumed from research that there was no significant relation of normal blood oxygen level with presence or absence of chin dimple.

\section{REFERENCES}

[1] Kosif R. Anatomical skin dimples. Innov J Med Health Sci. 2015; 5:15-8.

[2] Logothetis NK. The neural basis of the blood-oxygen-level-dependent functional magnetic resonance imaging signal. Philosophical Transactions of the Royal Society of London B: Biological Sciences. 2002 Aug 29; 357(1424):1003-37.

[3] Qadir MI, Saba G (2018) Awareness about intestinal cancer in university student. Nov Appro in Can Study, 1(3): NACS.000515.2018.

[4] Qadir MI, Ghalia BA (2018) Awareness survey about colorectal cancer in students of M. Phil Biotechnology at Bahauddin Zakariya University, Multan, Pakistan. Nov Appro in Can Study, 1(3): NACS.000514.2018.

[5] Qadir MI, Rizvi M (2018) Awareness about thalassemia in post graduate students. MOJ Lymphology \& Phlebology, 2(1): 14-16.

[6] Qadir MI, Shahzad R (2018) Awareness about obesity in postgraduate students of biotechnology. Int J Mod Pharma Res, 7(2): 14-16.

[7] Qadir MI, Mehwish (2018) Awareness about psoriasis disease. Int J Mod Pharma Res, 7(2): 17-18.

[8] Qadir MI, Ishfaq S (2018) Awareness about hypertension in biology students. Int J Mod Pharma Res, 7(2): 08-10

[9] Qadir MI, Saleem A (2018) Awareness about ischemic heart disease in university biotechnology students. Glo Adv Res J Med Medical Sci, 7(3): 059-061.

[10] Qadir MI, Javid A (2018) Awareness about Crohn's Disease in biotechnology students. Glo Adv Res J Med Medical Sci, 7(3): 062-064.

Citation: Muhammad Imran Qadir, Noor Arif, "Relation of Normal Blood Oxygen Level with Presence or Absence of Chin Dimple "International Journal of Research Studies In Biosciences (Ijrsb), Vol. 7, no. 5, pp. 23-25, 2019. http://Dx.Doi.org/10.20431/2349-0365.0705003

Copyright: (C) 2019 Authors. This is an open-access article distributed under the terms of the Creative Commons Attribution License, which permits unrestricted use, distribution, and reproduction in any medium, provided the original author and source are credited. 